\title{
Does clavicular shortening after nonoperative treatment of midshaft fractures affect shoulder function? A systematic review
}

\author{
Sarah Woltz $^{1}$ (I) Alysia Sengab $^{1} \cdot$ Pieta Krijnen $^{1} \cdot$ Inger B. Schipper $^{1}$
}

Received: 25 March 2017/Published online: 21 June 2017

(C) The Author(s) 2017. This article is an open access publication

\begin{abstract}
Introduction Clavicular shortening due to non-anatomical healing of displaced clavicular fractures is believed to have a negative effect on shoulder function after recovery. The evidence for this, however, is equivocal. This review aimed to systematically evaluate the available literature to determine whether the current beliefs about clavicular shortening can be substantiated.

Materials and methods This systematic review was performed following the Preferred Reporting Items for Systematic reviews and Meta-Analyses (PRISMA) statement. PubMed, EMBASE, Web of Science and the Clinical Trial Registry were searched to identify all studies published in English that evaluated the association between clavicular shortening and shoulder function in patients aged $\geq 16$ years with a nonoperatively treated, displaced midshaft clavicular fracture. Relevant data from the selected studies was extracted and summarized. Risk of bias of the included studies was assessed using the MINORS instrument.

Results Six studies, of which five were retrospective, were included in this review analyzing a total of 379 patients. Due to heterogeneity in methods and reporting across studies, a pooled analysis of the results was not feasible.
\end{abstract}

Electronic supplementary material The online version of this article (doi:10.1007/s00402-017-2734-7) contains supplementary material, which is available to authorized users.

Sarah Woltz and Alysia Sengab shared first authorship.

Sarah Woltz

s.woltz@lumc.nl

1 Department of Trauma Surgery, Leiden University Medical Center, P.O. Box 9600, 2300 RC Leiden, The Netherlands
No clear associations were found between shortening and shoulder function scores (DASH and Constant score) or arm strength in each of the included studies.

Conclusion The existing evidence to date does not allow for a valid conclusion regarding the influence of shortening on shoulder function after union of nonoperatively treated midshaft clavicular fractures. Shortening alone is currently not an evidence-based indication to operate for the goal of functional improvement. Well-powered prospective comparative studies are needed to draw firm conclusions.

Keywords Clavicular shortening · Shoulder function · Nonoperative treatment $\cdot$ Malunion

\section{Introduction}

Midshaft fractures of the clavicle are common and often displaced [1,2]. Treatment of these fractures is aimed at a complete recovery of the shoulder function, especially in younger patients. In nonoperatively treated patients, closed reduction of the fracture is difficult to achieve and to maintain, and is therefore no longer attempted [3, 4]. A certain degree of clavicular shortening often remains after union due to overlap of the fracture fragments, caused by traction of the pectoral and deltoid muscles and the weight of the arm that pull the lateral fragment ventro-caudally and medially, while the sternocleidomastoid muscle pulls the medial fragment upwards and dorsally [5].

In addition to the historic indications for operative fixation of displaced clavicular fractures (i.e., open fracture, neurovascular compromise and compromised skin), evidence-based reasons for operative fixation include reduction of the risk of nonunion and a quicker recovery [2, 6-8]. Substantial shortening of the clavicle is also 
considered to be an indication for operative treatment, partly because it may increase the risk of nonunion $[9,10]$, but also because shortening is thought to lead to a poorer functional outcome after fracture union. It is believed that the significant changes in the position of the glenoid fossa and shoulder girdle, and winging of the scapula after shortening of the clavicle are responsible [4, 11-13]. Also, muscle balance and tension can be reduced if the clavicle is shortened [12]. This altered anatomy may result in the sequelae that have been reported after nonoperative treatment $[4,9]$. Recent comparative studies, however, have not demonstrated a functional benefit for healed fractures after restoration of the anatomy with operative fixation compared with nonoperative treatment $[7,8]$.

It is important to clarify whether there is sufficient evidence to support the assumption that shortening is an indication for surgery to improve the functional outcome. Studies that have evaluated this relationship, however, show inconsistent results. While some reported that a larger shortening causes more complaints, pain and dissatisfaction $[9,14,15]$, others found no association between shortening and sequelae [16-18]. These studies, however, did not clearly evaluate an association with the function of the shoulder.

The aim of this review, therefore, was to summarize the available literature to evaluate whether clavicular shortening is negatively associated with shoulder function (i.e., patient-reported function, range of motion or arm strength) at latest follow-up after nonoperative treatment.

\section{Materials and methods}

This systematic review was performed according to the 'Preferred Reporting Items for Systematic reviews and Meta-Analyses: the PRISMA statement' [19].

\section{Search strategy and eligibility criteria}

The literature search was performed in Pubmed, Embase, Web of Science and the Clinical Trial Registry in December 2016. The search strategy was composed by an experienced medical librarian and combined various synonyms of the keywords 'clavicle', 'fracture', 'midshaft', 'nonoperative' and 'shortening' (see Supplementary Appendix 1 for the full search strategy).

Studies were eligible if they (1) included patients older than 15 years of age with a nonoperatively treated, displaced midshaft clavicular fracture, (2) evaluated the association between the extent of clavicular shortening and function of the shoulder (i.e., patient-reported functional outcome, range of motion and/or arm strength), and (3) were written in English.
Articles were excluded if they (1) included less than 20 patients, or (2) also analyzed medial and/or lateral clavicular fractures and the results for midshaft fractures were not reported separately. No date range was specified.

After removal of duplicates, the title and abstract of the identified articles were independently screened for eligibility by the first two authors. The full-text articles of the potentially relevant studies were read and judged for eligibility. The reference lists of these articles were searched for additional relevant studies, which were included if the above mentioned inclusion criteria applied. Disagreements were resolved by discussion.

\section{Data extraction}

From each included article, data were extracted by the first two authors, including study characteristics (study design, number of included patients and duration of follow-up) and patient characteristics (age, gender and type of nonoperative treatment). Outcomes of interest were clavicular shortening and shoulder function (measured by means of the DASH-score [20], Constant score [21], arm strength and/or range of motion), and the reported association between shortening and function. A meta-analysis could not be performed because there was considerable variation in the definitions of shortening and the statistical methods across studies.

\section{Quality assessment}

Methodological quality of the included studies was independently assessed by the first two authors using the "Methodological Index for Non-Randomized Studies" (MINORS) instrument, which consists of eight items regarding the design of non-comparative studies [22]. Each item is appointed a score (" $0 "=$ not reported; " $1 "=$ reported but inadequate; " 2 " = reported and adequate) with an optimal total score of 16 .

\section{Results}

\section{Literature search}

The search in Pubmed, Web of Science, Embase and the Clinical Trial Registry identified 151 potentially eligible articles. After removal of duplicates, 78 articles were screened based on title and abstract, of which 12 were selected. Screening the reference lists yielded another 7 potentially relevant articles. After reading the full text of these 19 articles, 6 articles were included in this systematic review based on the selection criteria (Fig. 1). 
Fig. 1 Flowchart of the included articles

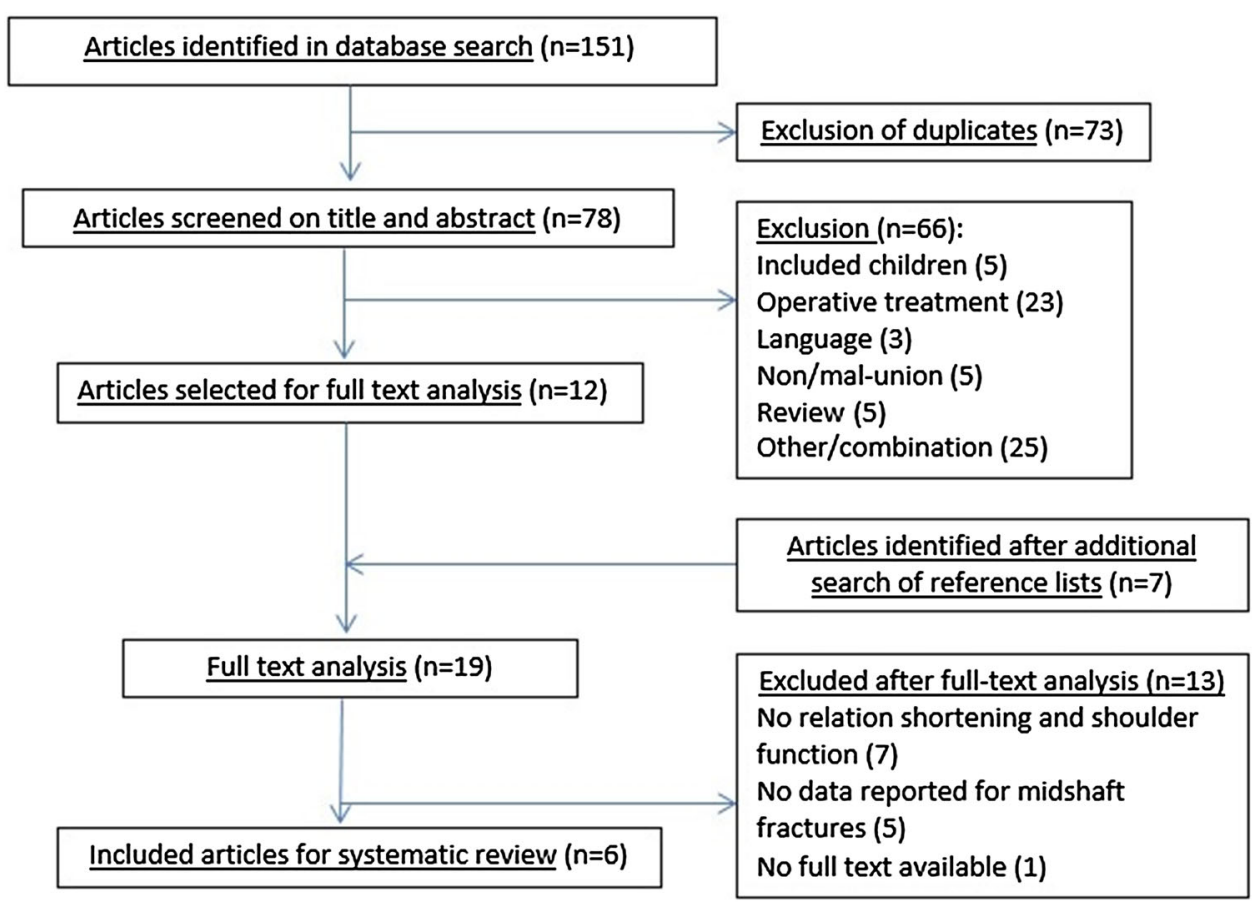

Table 1 Characteristics of the included studies and patients analyzed

\begin{tabular}{|c|c|c|c|c|c|c|}
\hline References & Study design & $\begin{array}{l}\text { No. of evaluated } \\
\text { patients }^{\mathrm{a}}\end{array}$ & $\begin{array}{l}\text { Mean time since } \\
\text { trauma, months }\end{array}$ & $\begin{array}{l}\text { Mean age, } \\
\text { years (SD) }\end{array}$ & $\begin{array}{l}\text { Male } \\
(\%)\end{array}$ & Type of nonoperative treatment \\
\hline Fuglesang et al. [26] & Retrospective & $59 / 92$ & $32(12-59)$ & $39.1(12.3)$ & 83 & Sling \\
\hline Figueiredo et al. [27] & Prospective & $54 / 59$ & 12 & $34(13)$ & 81 & $\mathrm{FEB}+\mathrm{PT}$ \\
\hline Stegeman et al. [23] & Retrospective & $32 / 74$ & $12-72$ & $\begin{array}{l}\text { Median } 31 \\
\quad \text { (range 21-62) }\end{array}$ & 84 & Not reported \\
\hline Rasmussen et al. [24] & Retrospective & $136 / 237$ & $55(24-83)$ & $35(15)$ & 79 & $\begin{array}{c}\text { FEB }(n=50) \text {, simple sling }(n=70) \text {, } \\
\text { C\&C }(n=13) \text {, no support }(n=3)\end{array}$ \\
\hline Postacchini et al. [25] & Retrospective & $68 / 119^{b}$ & 104 & 36.9 & 65 & Sling or FEB \\
\hline McKee et al. [5] & Retrospective & $30 / 63$ & $55(12-72)$ & 37 & 73 & Sling \\
\hline
\end{tabular}

$S D$ standard deviation, FEB figure of eight bandage, $C \& C$ collar and cuff, $P T$ physiotherapy

a No of evaluated patients/no of eligible patients (or included patients for prospective study)

b 119 patients were eligible for inclusion in total. Number of eligible patients with Allman type 1b/c fracture not stated

\section{Study characteristics}

The included studies were published between 2006 and 2015, and evaluated a total of 379 patients (Table 1). Five studies were retrospective [5, 23-26] and one was prospective [27]. In four studies, determining the relationship between shortening and shoulder function was the primary study aim $[23,24,26,27]$. Follow-up was at least 12 months in all studies, with a frequency-weighed mean of 4.5 years. Most patients were immobilized with a sling or figure-of-eight bandage for various time periods. The prospective study reported a loss to followup of $8.5 \%$ [27].

\section{Clavicular shortening}

The studies expressed clavicular shortening in different ways; either by measuring the difference in length between the injured and the contralateral clavicle [5, 24, 27], or by measuring the overlap of fracture fragments [26]. Stegeman and Postacchini additionally calculated the proportional shortening by dividing the overlap of fracture fragments by the sum of the length of the injured clavicle and the measured overlap [23, 25]. Shortening was also measured at different time points: on the index trauma radiographs [24-27], or on radiographs taken after the fracture had united [5, 23]. 
The reported mean shortening (Table 2) ranged from $9.2 \mathrm{~mm}$ (SD 6.4) to $25 \mathrm{~mm}$ (SD 16). Three studies compared patients with a shortening less than $20 \mathrm{~mm}$ with those having $20 \mathrm{~mm}$ or more shortening. In these studies, 15,37 and $19 \%$ of the study population had a shortening

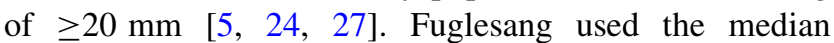
shortening of $15 \mathrm{~mm}$ as cut-off value to determine small or large shortening, thus creating two equally sized groups [26].

\section{Shoulder function}

Various outcome measures were used to evaluate shoulder function at final follow-up. Mean DASH scores ranged from 3.38 to 24.6 in four studies (Table 2) [5, 23, 26, 27]. The mean Constant score (Table 2) was reported in five studies (range 71-96) [5, 23-26]. McKee found much poorer mean Constant and DASH scores than the other studies, and both functional scores were significantly worse than the normative value for the general population (71 vs 92 and 24.6 vs 10.1 , respectively) [5, 28, 29]. One study that compared the injured with the healthy shoulder, reported a significant difference in Constant score (86.3 vs 93.7, $p<0.001$ ) [24], whereas Constant and DASH scores of the patients in another study were similar to those of matched controls [23].
Strength was measured by Stegeman and McKee with a hand-held dynamometer and with the Baltimore Therapeutic Equipment (BTE) Work Simulator, respectively $[5,23]$. Whereas Stegeman found no significant mean differences in strength compared with the contralateral shoulder for six different motions, McKee reported that the injured shoulder had $81-85 \%$ of the strength and $67-82 \%$ of the endurance of the patients' uninjured shoulder ( $p<0.05$ for all motions) (Table 3 ).

Three studies reported the range of motion of the injured and contralateral shoulders but did not analyze its association with clavicular shortening [5, 23, 25]. For this reason, results on range of motion are not included in this review.

\section{Association between shortening and shoulder function}

The association between clavicular shortening and the DASH score was analyzed in three studies. Results are presented in Table 2. No statistically significant linear correlations were found $[5,27]$. Also, no difference in DASH scores existed between patient groups when shortening was dichotomized using cut-off values of $15 \mathrm{~mm}$ [26] or $20 \mathrm{~mm}$ [27].

McKee reported that among patients with $\geq 20 \mathrm{~mm}$ shortening, a poor DASH score of $>30$ seemed more

Table 2 Relation between clavicular shortening and Constant score and/or DASH score

\begin{tabular}{|c|c|c|c|c|}
\hline References & Mean shortening in mm (SD) & Mean Constant score (SD) & Mean DASH score (SD) & Correlation $(r)$ or $p$ value \\
\hline \multirow[t]{3}{*}{ Fuglesang et al. [26] } & $17.1(7.1)$ & 81 (69-90) (median) & $6.7(0.8-19)$ (median) & \\
\hline & $<15 \mathrm{~mm}: n \approx 30$ & $80(64-88)$ & $7(3-27)$ & $p=0.5($ constant $)$ \\
\hline & $>15 \mathrm{~mm}: n \approx 30$ & $84(74-90)$ & $7(0-11)$ & $p=0.1(\mathrm{DASH})$ \\
\hline \multirow[t]{3}{*}{ Figueiredo et al. [27] } & $9.2(6.4)$ & N/A & $3.38(9.21)$ & $r=-0.017 ; p=0.90$ \\
\hline & $<20 \mathrm{~mm}: n=47(81 \%)$ & & 3.38 (CI 9.56) & $p=0.53$ \\
\hline & $>20 \mathrm{~mm}: n=11(19 \%)$ & & 3.33 (CI 7.02) & \\
\hline \multirow[t]{3}{*}{ Rasmussen et al. [24] } & $11.6(8.2)$ & $86.3(29-100)$ & N/A & $r=0.14 ; p>0.05$ \\
\hline & $<20: n=116(85 \%)$ & $7.2(10.3)^{\mathrm{a}}$ & & $p=0.79$ \\
\hline & $>20: n=20(15 \%)$ & $7.9(10.3)$ & & \\
\hline \multirow[t]{4}{*}{ Postacchini et al. [25] } & Males: 14.1 (8.9); & Allman $1 \mathrm{~B}^{\mathrm{c}}: 87.1$ & N/A & \\
\hline & $8.9 \%(5.6 \%)^{\mathrm{b}}$ & Allman 1C: 85.6 & & \\
\hline & Females: $10.9(7.8) ; 8.3 \%(6.0 \%)^{1}$ & $\mathrm{CS} \geq 90(n=55): 7.7 \%$ & & $p<0.05$ \\
\hline & & $\mathrm{CS} \leq 80(n=9): 13.2 \%$ & & \\
\hline \multirow[t]{6}{*}{ McKee et al. [5] } & $14.5(8.6)$ & 71 (SD not given) & 24.6 (SD not given) & $r=-0.20 ; p=0.44$ \\
\hline & & & & $r=0.32 ; p=0.11$ \\
\hline & $<20 \mathrm{~mm}: n=19(63 \%)$ & & & $p=0.06$ \\
\hline & $\geq 20 \mathrm{~mm}: n=11(37 \%)$ & & DASH $>30$ points: & \\
\hline & & & $3 / 19(16 \%)$ & \\
\hline & & & $7 / 11(64 \%)$ & \\
\hline
\end{tabular}

\footnotetext{
${ }^{a}$ Mean difference in Constant score between injured and uninjured shoulder

b Proportional shortening: overlap of fracture fragments divided by sum of overlap and length of injured clavicle

c Allman type 1B: displaced fractures, Allman type 1C: displaced with third bone fragment
} 
Table 3 Relation between clavicular shortening and shoulder strength

\begin{tabular}{|c|c|c|c|}
\hline References & Mean shortening in $\mathrm{mm}(\mathrm{SD})$ & Mean strength in Newton (95\% CI) & Correlation or $p$ value \\
\hline \multirow[t]{6}{*}{ Stegeman et al. [23] } & $25(16)$ & Adduction: $7.2(-3.5 \text { to } 18)^{\mathrm{b}}$ & $\beta=-1.29(p=0.07)$ \\
\hline & $13 \%(8 \%)^{\mathrm{a}}$ & Abduction: -0.1 ( -8.8 to 8.6$)$ & $\beta=-0.47(p=0.4)$ \\
\hline & & Anteflexion: 9.6 ( -3.1 to 22$)$ & $\beta=0.59(p=0.5)$ \\
\hline & & Retroflexion: 14.6 ( -6.7 to 9.8 ) & $\beta=-0.08(p=0.9)$ \\
\hline & & Exorotation: $2.0(-3.2$ to 7.3$)$ & $\beta=0.08(p=0.8)$ \\
\hline & & Endorotation: 5.1 ( -0.8 to 11.1$)$ & $\beta=0.37(p=0.3)$ \\
\hline \multirow[t]{4}{*}{ McKee et al. [5] } & $14.5(8.6$ & Flexion: $81 \%, 75 \%{ }^{\mathrm{c}}$ & $\mathrm{ns}$ \\
\hline & & Abduction: $82 \%, 67 \%$ & $r=-0.32(p=0.06)$ \\
\hline & $<20: n=19(63 \%)$ & Exorotation: $81 \%, 82 \%$ & $\mathrm{~ns}$ \\
\hline & $\geq 20: n=11(37 \%)$ & Endorotation: $85 \%, 78 \%$ & $\mathrm{~ns}$ \\
\hline
\end{tabular}

a Proportional shortening: overlap of fracture fragments divided by sum of overlap and length of injured clavicle

${ }^{\mathrm{b}}$ Difference in strength between uninjured and injured shoulder. $p>0.05$ for all comparisons

${ }^{c}$ Strength and endurance of injured shoulder as a percentage of the uninjured shoulder

Table 4 Methodological quality of included studies assessed according to the Methodological Index for Non-Randomized Studies (MINORS) instrument [20]

\begin{tabular}{|c|c|c|c|c|c|c|}
\hline & $\begin{array}{l}\text { Fugle-sang } \\
\text { et al. [26] }\end{array}$ & $\begin{array}{l}\text { Figueiredo } \\
\text { et al. [27] }\end{array}$ & $\begin{array}{l}\text { Stege-man } \\
\text { et al. [23] }\end{array}$ & $\begin{array}{l}\text { Rasmussen } \\
\text { et al. [24] }\end{array}$ & $\begin{array}{l}\text { Postac-chini } \\
\text { et al. [25] }\end{array}$ & $\begin{array}{l}\text { McKee } \\
\text { et al. [5] }\end{array}$ \\
\hline 1. A clearly stated aim & 2 & 2 & 2 & 2 & 2 & 2 \\
\hline 2. Inclusion of consecutive patients & 1 & 2 & 1 & 1 & 1 & 1 \\
\hline 3. Prospective collection of data ${ }^{a}$ & 2 & 2 & 2 & 2 & 2 & 2 \\
\hline 4. Endpoints appropriate to the aim of the study & 2 & 2 & 2 & 2 & 2 & 2 \\
\hline 5. Unbiased assessment of the study endpoint & 0 & 0 & 0 & 0 & 1 & 1 \\
\hline 6. Follow-up period appropriate to the aim of the study & 2 & 2 & 2 & 2 & 2 & 2 \\
\hline 7. Loss to follow-up less than $5 \%$ & 2 & 1 & 2 & 2 & 2 & 2 \\
\hline 8. Prospective calculation of the study size & 0 & 0 & 1 & 0 & 0 & 0 \\
\hline Total & 11 & 11 & 12 & 11 & 12 & 12 \\
\hline
\end{tabular}

The items are scored 0 (not reported), 1 (reported but inadequate) or 2 (reported and adequate). Maximum score is 16

${ }^{a}$ Data were collected according to a protocol established before the beginning of the study

prevalent than among patients with $<20 \mathrm{~mm}$ shortening (64 vs $16 \%, p=0.06)$ [5].

Four articles reported on the association between shortening and Constant score (Table 2) [5, 24-26]. No linear relationship was found $[5,24]$. Also, a larger shortening (more than 20 or $15 \mathrm{~mm}$ ) did not result in a significantly lower Constant score $[24,26]$. Only Postacchini found that shortening was significantly larger in patients with a Constant score below 80, than in patients with a Constant score of 90 or higher [25]. Stegeman reported that all DASH and Constant scores were in the normal range of values, and therefore, did not analyze a relation with shortening [23].

Two studies evaluated arm strength (Table 3) [5, 23]. Only the association between shortening and abduction endurance approached statistical significance in one study [5]. There was no relation between shortening and endurance for all other motions, nor with strength $[5,23]$.

\section{Risk of bias and quality assessment}

Table 4 shows the results for the assessment of the methodological quality for each study. All studies had a clear aim and collected appropriate data according to a beforehand established protocol. In most studies, however, there was risk of observer bias because function scores and shortening were measured by the same researcher, and of selection bias because only a portion of the eligible patients participated. Only one study mentioned the intended sample size, but no calculation or rationale was stated [23]. 


\section{Discussion}

In daily practice, shortening of a midshaft clavicular fracture is often regarded as a risk factor for functional impairment after fracture union. This review of the available literature included six studies and showed that there is not enough evidence to substantiate this assumption. Therefore, shortening of a fractured clavicle should currently not be regarded as an evidence-based indication to operate for the goal of functional improvement. In a clear evidence-supported approach, other indications should be considered such as the reduced risk of nonunion and earlier functional recovery. Also, following the principles of shared decision making, patients' preferences could be reason to opt for surgical treatment.

A difficulty in studying possible influences on shoulder function is that Constant and DASH scores are generally in the upper range of the scale after clavicular fractures. Due to this ceiling-effect subtle differences in scores remain undetected, although such small differences in scores are unlikely to be clinically relevant for most patients. Also, the number of patients with a large amount of shortening in the included studies was low. For instance, the association that was found between a larger shortening and a Constant score below 80 in one study, was based on only nine patients [25].

The most important limitation of this review is the heterogeneity in methods and definitions across studies. The research groups obviously differed in their ideas about the best way to measure clavicular shortening. Most conspicuous are the different time points at which shortening was measured; either directly after the injury, or after fracture union. Fuglesang reported that the median difference in clavicular length between initial and final radiographs was $7.5 \mathrm{~mm}$ (25th-75th percentiles 4-10), and that there were large individual adjustments suggesting that the final amount of shortening cannot be reliably predicted on initial radiographs [26]. Two previous studies by Smekal et al., however, showed no significant difference between initial and final proportional shortening [5.4 (SD 4.0) vs 4.7 (SD 3.9), $p=0.16$; and 5.0 (SD 3.3) vs 5.1 (SD 3.5), $p=0.86][30,31]$.

Also, different techniques were applied to measure shortening. Three studies used the length of the contralateral clavicle, assuming that the clavicles had been equally long before fracture $[5,24,27]$. It is, however, well known that a considerable asymmetry of both clavicles may exist within individuals: a mean difference in clavicular length of $4.25 \mathrm{~mm}$ (SD 3.8) and an asymmetry of $\geq 5 \mathrm{~mm}$ in $28.5 \%$ of uninjured, skeletally mature adults has been reported [32].

In addition, four of the studies expressed shortening as the absolute difference in clavicular length [5, 24, 26, 27].
A large absolute shortening, however, potentially has more influence on shoulder kinematics in a patient with a short clavicle than in a tall patient with a long clavicle [33]. Stegeman and Postacchini accounted for these issues by expressing shortening as a proportion of the clavicular length, and using the estimated length of the original bone instead of the contralateral clavicle for comparison $[23,25]$.

In summary, the existing evidence to date does not allow for a valid conclusion regarding the influence of shortening on shoulder function after union of nonoperatively treated midshaft clavicular fractures. Shortening alone is currently not an evidence-based indication to operate for the goal of functional improvement. Well-designed prospective studies including sufficient numbers of patients with a substantial amount of shortening are needed to formulate a conclusion.

\section{Compliance with ethical standards}

Conflict of interest The authors declare that they have no conflict of interest.

Funding There is no funding source.

Ethical approval This article does not contain any studies with human participants or animals performed by any of the authors.

Open Access This article is distributed under the terms of the Creative Commons Attribution 4.0 International License (http://crea tivecommons.org/licenses/by/4.0/), which permits unrestricted use, distribution, and reproduction in any medium, provided you give appropriate credit to the original author(s) and the source, provide a link to the Creative Commons license, and indicate if changes were made.

\section{References}

1. Robinson CM (1998) Fractures of the clavicle in the adult. Epidemiology and classification. J Bone Jt Surg Br 80(3):476-484

2. Lenza M, Buchbinder R, Johnston RV, Belloti JC, Faloppa F (2013) Surgical versus conservative interventions for treating fractures of the middle third of the clavicle. Cochrane Database Syst Rev (6):CD009363. doi:10.1002/14651858.CD009363.pub2

3. Rowe CR (1968) An atlas of anatomy and treatment of midclavicular fractures. Clin Orthop Relat Res 58:29-42

4. Hillen R, Burger B, Pöll R, van Dijk C, Veeger D (2012) The effect of experimental shortening of the clavicle on shoulder kinematics. Clin Biomech 27(8):777-781

5. McKee M, Pedersen E, Jones C, Stephen DJ, Kreder HJ, Schemitsch EH, Wild LM, Potter JM (2006) Deficits following nonoperative treatment of displaced midshaft clavicular fractures. J Bone Jt Surg Am 88(1):35-40

6. Canadian Orthopaedic Trauma Society (2007) Nonoperative treatment compared with plate fixation of displaced midshaft clavicular fractures. A multicenter, randomized clinical trial. J Bone Jt Surg Am 89(1):1-10

7. Robinson CM, Goudie EB, Murray IR, Jenkins PJ, Ahktar MA, Read EO, Foster CJ, Clark K, Brooksbank AJ, Arthur A, 
Crowther MA, Packham I, Chesser TJ (2013) Open reduction and plate fixation versus nonoperative treatment for displaced midshaft clavicular fractures: a multicenter, randomized, controlled trial. J Bone Jt Surg Am 95(17):1576-1584

8. Woltz S, Stegeman SA, Krijnen P, van Dijkman BA, van Thiel TP, Schep NW, de Rijcke PA, Frölke JP, Schipper IB (2017) Plate fixation compared with nonoperative treatment for displaced midshaft clavicular fractures: a multicenter randomized controlled trial. J Bone Jt Surg Am 99(2):106-112

9. Hill JM (1997) Closed treatment of displaced middle-third fractures of the clavicle gives poor results. J Bone Jt Surg Br 79(4):537-539

10. Murray IR, Foster CJ, Eros A, Robinson CM (2013) Risk factors for nonunion after nonoperative treatment of displaced midshaft fractures of the clavicle. J Bone Jt Surg Am 95(13):1153-1158

11. Andermahr J, Jubel A, Elsner A, Prokop A, Tsikaras P, Jupiter J, Koebke J (2006) Malunion of the clavicle causes significant glenoid malposition: a quantitative anatomic investigation. Surg Radiol Anat 28(5):447-456

12. Ledger M, Leeks N, Ackland T, Wang A (2005) Short malunions of the clavicle: an anatomic and functional study. J Shoulder Elbow Surg 14(4):349-354

13. Su WR, Chen WL, Chen RH, Hong CK, Jou IM, Lin CL (2016) Evaluation of three-dimensional scapular kinematics and shoulder function in patients with short malunion of clavicle fractures. J Orthop Sci 21(6):739-744

14. Eskola A, Vainionpii S, Myllynen P, Patiala H, Rokkanen P (1986) Outcome of clavicular fracture in 89 patients. Arch Orthop Trauma Surg 105:337-338

15. Lazarides S, Zafiropoulos G (2006) Conservative treatment of fractures at the middle third of the clavicle: the relevance of shortening and clinical outcome. J Shoulder Elbow Surg 15(2):191-194

16. Oroko P, Buchan M, Winkler A, Kelly I (1999) Does shortening matter after clavicular fractures? Bull Hosp Jt Dis 58(1):6-8

17. Nordqvist A, Redlund-Johnell I, von Scheele A, Petersson CJ (2009) Shortening of clavicle after fracture: incidence and clinical significance, a 5-year follow-up of 85 patients. Acta Orthop Scand 68(4):349-351

18. Nowak J, Holgersson M, Larsson S (2004) Can we predict longterm sequelae after fractures of the clavicle based on initial findings? A prospective study with nine to ten years of follow-up. J Shoulder Elbow Surg 13(5):479-486

19. Moher D, Liberati A, Tetzlaff J, Altman DG, The PRISMA Group (2009) Preferred reporting items for systematic reviews and meta-analyses: the PRISMA statement. PLoS Med 6(7):e1000097

20. Beaton DE, Katz JN, Fossel AH, Wright JG, Tarasuk V, Bombardier C (2001) Measuring the whole or the parts? Validity, reliability, and responsiveness of the disabilities of the arm, shoulder and hand outcome measure in different regions of the upper extremity. J Hand Ther 14(2):128-146
21. Constant CR, Gerber C, Emery RJ, Sojbjerg JO, Gohlke F, Boileau P (2008) A review of the Constant score: modifications and guidelines for its use. J Shoulder Elbow Surg 17(2):355-361

22. Slim K, Nini E, Forestier D, Kwiatkowski F, Panis Y, Chipponi J (2003) Methodological index for non-randomized studies (minors): development and validation of a new instrument. ANZ J Surg 73(9):712-716

23. Stegeman SA, de Witte PB, Boonstra S, de Groot JH, Nagels J, Krijnen P, Schipper IB (2015) Posttraumatic midshaft clavicular shortening does not result in relevant functional outcome changes. Observations in 32 healed, nonoperatively treated fractures. Acta Orthop 86(5):1-8

24. Rasmussen JV, Jensen SL, Petersen JB, Falstie-Jensen T, Lausten G, Olsen BS (2011) A retrospective study of the association between shortening of the clavicle after fracture and the clinical outcome in 136 patients. Injury 42(4):414-417

25. Postacchini R, Gumina S, Farsetti P, Postacchini F (2010) Longterm results of conservative management of midshaft clavicle fracture. Int Orthop 34(5):731-736

26. Fuglesang HF, Flugsrud GB, Randsborg PH, Stavem K, Utvag SE (2016) Radiological and functional outcomes 2.7 years following conservatively treated completely displaced midshaft clavicle fractures. Arch Orthop Trauma Surg 136(1):17-25

27. Figueiredo GS, Tamaoki MJ, Dragone B, Utino AY, Netto NA, Matsumoto MH, Matsunaga FT (2015) Correlation of the degree of clavicle shortening after non-surgical treatment of midshaft fractures with upper limb function. BMC Musculoskelet Disord $16: 151$

28. Yian EH, Ramappa AJ, Arneberg O, Gerber C (2005) The Constant score in normal shoulders. J Shoulder Elbow Surg 14(2):128-133

29. Hunsaker F, Cioffi D, Amadio P, Wright JG, Caughlin B (2002) The American Academy of Orthopaedic Surgeons. Outcomes instruments: normative values from the general population. J Bone Jt Surg Am 84-A(2):208-215

30. Smekal V, Irenberger A, Struve P, Wambacher M, Krappinger D, Kralinger FS (2009) Elastic stable intramedullary nailing versus nonoperative treatment of displaced midshaft clavicular fractures - a randomized, controlled, clinical trial. J Orthop Trauma 23(2):106-112

31. Smekal V, Irenberger A, Attal RE, Oberladstaetter J, Krappinger D, Kralinger F (2011) Elastic stable intramedullary nailing is best for mid-shaft clavicular fractures without comminution: results in 60 patients. Injury 42(4):324-329

32. Cunningham BP, McLaren A, Richardson M, McLemore R (2013) Clavicular length: the assumption of symmetry. Orthopedics 36(3):e343-e347

33. De Giorgi S, Notarnicola A, Tafuri S, Solarino G, Moretti L, Moretti B (2011) Conservative treatment of fractures of the clavicle. BMC Res Notes 4:333 